\title{
O ENCONTRO "OS 25 DE EDUCAÇÃO EM BIBLIOTECONOMIA NA UNIVERSIDADE FEDERAL DE SANTA CATARINA"
}

\author{
Prof ${ }^{\mathrm{o}}$. Dr. Francisco das Chagas de Souza \\ Presidente do Colegiado do Curso de Biblioteconomia da \\ Universidade Federal de Santa Catarina e \\ Coordenador do Encontros dos 25 anos - e-mail: chagas@ced.ufsc.br
}

\begin{abstract}
RESUMO
Relata o ENCONTRO DOS 25 ANOS DE EDUCAÇÃO EM BIBLIOTECONOMIA NA UNIVERSIDADE FEDERAL DE SANTA CATARINA, de 26 a 27 de outubro de 1998, realizado no Auditório do Centro de Ciências da Educação, da Universidade Federal de Santa Catarina.
\end{abstract}

PALAVRAS-CHAVE: Curso de Biblioteconomia

\begin{abstract}
Report of the the 25 years Meeting of Education on Library Science held at the Science Education Center of the Federal University of Santa Catarina, Florianópolis, Brazil, on October 26 and 27, 1998.
\end{abstract}

KEYWORDS: Library Science Education, Federal University of Santa Catarina - Brazil

Na sua abertura dizíamos: "Iniciamos, a partir de agora, e percorreremos nestes dois dias, o tratamento de uma história de 25 anos, com a intenção de podermos dar um novo salto e podermos fazer muito melhor o que de melhor se pode fazer em Educação Bibioteconômica nesta IES.

Para lhes falar nestes minutos escassos, que são próprios de uma abertura, fiquei a refletir nas últimas horas sobre o que dizer. Dentre as várias possibilidades olhei para mim mesmo e perguntei-me: o que eu sabia sobre a Ciência Biblioteconômica e sobre a Educação em Biblioteconomia, em 1973, ou seja, há 25 anos? E vi-me não sabendo nada sobre as mesmas. E, não sabia, mesmo sendo um usuário assíduo de bibliotecas, destacando a freqüência regular à Biblioteca Pública Estadual Governador Menezes Pimentel, em Fortaleza, que conheci ainda instalada no antigo Palácio da Luz, ao lado da Praça dos Leões, bem perto do Mercado Central e à Biblioteca Municipal de Fortaleza Professor Dolor Barreira, bem próxima do centro da cidade, localizada, então, na Av. Duque de Caxias.

Apesar de conhecer bibliotecas tratadas com os requisitos do conhecimento biblioteconômico, as conhecia como qualquer usuário de serviços, não fazendo a menor idéia do que ocorria por trás do balcão ou birô de atendimento; nunca ouvira falar de que seria necessária uma formação escolar específica de pessoas que fariam a organização científica das coleções e o atendimento qualifícado do público; nunca me dera conta de que usava setores batizados como coleção de referência, coleção geral, etc. Sabia mesmo era que, em geral, lia os livros, jornais e outros documentos que me interessavam. E vejam que eu estava em uma cidade, Fortaleza, que, então, dispunha de um Curso de Biblioteconomia, na Universidade Federal do Ceará, há 9 anos, pois fora criado em 1964 e onde também ocorrera um Congresso Brasileiro de Biblioteconomia ? há 10 anos? em 1963.

Só descobri a Biblioteconomia em 1975 e não por via da Universidade que oferecia o Curso. A descoberta deu-se quando estava decidindo a escolha para o Vestibular. Nesta época eu freqüentava um Curso Técnico de Contabilidade e atuava no Departamento de Pessoal do Banco do Nordeste do Brasil, no setor de arquivo. Por ter que decidir sobre a escolha para o Vestibular consultei fontes de informação sobre as profissões e ali descobri o perfil desta profissão, vendo sua relação com o que eu fazia no BNB. Na inscrição para o Vestibular, que exigia dupla opção, marquei 1 - Biblioteconomia e 2 - Direito e, no caso, se tivesse feito a opção inversa teria entrado no Ensino Superior, igualmente, iniciando o Curso em 1976 e concluindo-o em 1978.

Enc. Bibli: R. Eletr. Bibliotecon. Ci. Inf., ISSN 1518-2924, Florianópolis, Brasil. 
Nestes meus 23 anos de acumulação de conhecimento sobre a Ciência Biblioteconômica, incluídos os 15 anos de envolvimento, como Professor, com a Educação Biblioteconômica, sei que o ponto fraco da Biblioteconomia e da Educação em Biblioteconomia no Brasil é a pequena quantidade de publicações que sobre ela se produz e que seus profissionais produzem. E é, por isso, principalmente, que ela tem recebido tão pouca publicidade, fazendo com que, os mais contumazes usuários de bibliotecas não façam a menor idéia dos processos que se desenrolam para que eles possam alcançar proveitosamente a informação de que necessitam ou pela qual se interessam.

É nesse rumo que acho que devemos investir ? na publicização da biblioteconomia ? enlace no qual se inserem eventos, revistas, livros e toda e qualquer produção que possa disseminar do modo mais amplo possível, para a sociedade, o que se cria e se faz no campo da Ciência Biblioteconômica.

Assim, determinado por seus objetivos imediatos, conforme se lê em seu "folder" de divulgação, este Encontro OS VINTE E CINCO ANOS DA EDUCAÇÃO EM BIBLIOTECONOMIA NA UFSC quer, acima de tudo, na sua pretensão de constituir memória, ser uma fonte de inspiração para ações futuras e quer dar conteúdo para a produção de divulgação que possa elucidar para os que usam informação o que fez e o que pretende fazer o Curso de Biblioteconomia da UFSC".

Dentre os temas abordados no ENCONTRO, foi realizado em forma de painel - Marcos do ensino de biblioteconomia na UFSC, pelas professoras Maria del Carmen Rivera Bohn, Clarice Fortkamp Caldin, Estera Muszkat Menezes, Maria Margarete Sell da Mata, Gleisy Regina Bories Fachin e Eliana Maria dos Santos Bahia do Departamento de Biblioteconomia e Documentação.

O tema Educação sem informação ? informação sem educação, em forma de palestra, foi apresentado pelo Dr. Luiz Augusto Milanesi, da ECA/USP.

O tema Educação pela pesquisa: desafio para o ensino de biblioteconomia na UFSC, foi apresentado em forma de palestra, com a participação do Dr. Lucício Biancheti, do CED/UFSC.

No ENCONTRO foram realizados o lançamento da Revista ACB, v. 3 - 1998; o lançamento do periódico eletrônico Encontros BIBLI, n. 6, 09/98; mostrada no hall do Centro de Ciência da Educação a Exposição "O FAROL DO SABER", trabalho realizado por alunas do Curso de Biblioteconomia em visita às bibliotecas públicas de Curitiba.

Por fim, foi inaugurada a Exposição Eletrônica: 25 anos de Biblioteconomia em SC, uma página elaborada por professores do Departamento de Biblioteconomia e Documentação, liderados pela Professora Eliana Maria dos Santos Bahia, com o apoio técnica de Cecília S. Machado.

Como parte do ENCONTRO realizou-se solenidade de homenagem aos Fundadores do Curso de Biblioteconomia, sendo entregues três placas da seguinte maneira: uma para o Professor Roberto Mündel de Lacerda - Reitor da época; outra para a Viúva do Professor Glauco Rodrigues Corrêa (em memória), primeiro Integrador do Curso de Biblioteconomia e a terceira para a Professora Alvaceli Lusa Braga a autora do Projeto de criação do Curso e uma das primeiras professoras do novo curso.

Do Encontro participaram, com inscrição registrada, 217 pessoas, sendo 6 estudantes da UDESC, 4 profissionais bibliotecários, 1 estudante de Pedagogia, 1 estudante de Letras e os demais, estudantes do Curso de Biblioteconomia da UFSC.

Atendendo ao convite da Coordenação do ENCONTRO participaram da abertura as seguintes pessoas representando as entidades designadas:

Professor Faruk José Nome Aguilera - Pró-Reitor de Ensino de Graduação, Representando o Magnífico Reitor da Universidade Federal de Santa Catarina

Professora Vera Lúcia Bazzo - Diretora do Centro de Ciências da Educação da Universidade Federal de 
Santa Catarina

Bacharel Carmelita Tomasoni - Presidente da Associação Catarinense de Bibliotecários

Bacharel Maria Aparecida Sell - Presidente do Conselho Regional de Biblioteconomia da 14a. Região, sediado no Estado de Santa Catarina

Acadêmica Maria Guilhermina Salasário - Presidente do Centro Acadêmico do Curso de Biblioteconomia da Universidade Federal de Santa Catarina

Professora Maria Emília Ganzarolli Martins - Coordenadora do Curso de Biblioteconomia da

Universidade para o Desenvolvimento do Estado de Santa Catarina

A mesa da sessão de encerramento contou com a seguinte composição:

- Professora Ana Beatriz Cerizara, Vice-Diretora do CED, representando a Sra. Diretora do Centro de Ciências da Educação da UFSC;

- Professora Edna Lúcia da Silva, representando os formandos das turmas de 1976;

- Acadêmica Maria Guilhermina Salasário - Presidente do Centro Acadêmico do Curso de Biblioteconomia da UFSC;

- Bacharel Carmelita Tomasoni - Presidente da Associação Catarinense de Bibliotecários;

- Bacharel Maria Aparecida Sell - Presidente do Conselho Regional de Biblioteconomia da 14a. Região;

- Bacharel Marlene Filomeno Machado Ribeiro - Diretora da Biblioteca do Município de Florianópolis.

Aos participantes inscritos no ENCONTRO foi fornecido o instrumento de avaliação que, ao ser respondido, ofertaria ao Curso de Biblioteconomia valiosa contribuição para o planejamento e execução de novos eventos.

Os Resultados obtidos com a apuração das respostas devolvidas por 132 participantes, são as seguintes: . para a questão 1 - respondidos 121 instrumentos . para a questão 2 - respondidos 124 instrumentos . para a questão 3 - respondidos 114 instrumentos . para a questão 4 - respondidos 123 instrumentos, sendo 100 - a) Muito interesse, com 86 comentados e 23 - b) Razoável interesse, com 13 comentados.

Houve a manifestação espontânea de 16 respondentes que chamaram a atenção para a limitação do espaço físico utilizado para abrigar o Encontro.

$\mathrm{Na}$ apuração das respostas se considerou mais de uma resposta para a mesma questão, bem como a linguagem do próprio respondente.

Analisando os instrumentos, questão por questão, tem-se os resultados que seguem:

Questão 1 - Por qual razão você participou deste Evento?

. Para conhecer melhor o Curso de Biblioteconomia da UFSC

Por interesse em aprender mais sobre a área de Biblioteconomia 28

. Para buscar novos conhecimentos

. Por interesse

. Para Conhecer as possibilidades profissionais futuras

. Prestigiar o trabalho realizado pela organização do evento

Pela programação de palestras

. Por ser aluna do curso

Por curiosidade

. Para interagir com os demais alunos e professores

. Para conhecer o método

Para fazer relatório

\section{8}

5

4

3

3

2

2

1

1

Questão 2 - Para você, quais foram os pontos fortes no conteúdo e na apresentação dos seguintes temas:

a) Marcos do Ensino de Biblioteconomia na UFSC

$>$ a palestra como um todo

$>$ A história do Curso

Enc. Bibli: R. Eletr. Bibliotecon. Ci. Inf., ISSN 1518-2924, Florianópolis, Brasil. 
$>$ Clareza e objetividade

$>$ Os itens sobre pesquisa e extensão

$>$ O material usado

$>$ A dinâmica do Curso refletida na mudança da missão

b) Educação sem informação, informação sem educação

$>$ A palestra como um todo

$>$ Levou à reflexão

$>$ Deu ênfase na formação de bibliotecário para a sociedade $\quad 12$

$>$ Enfatizou o esquecimento das bibliotecas escolares 7

$>$ Enfatizou o bibliotecário como educador $\quad 2$

$>$ Mostrou a grande diferença entre educação e informação 1

$>$ O palestrante tem facilidade de comunicação

$>$ Enfatizou que o professor deve dar ao aluno a liberdade de criar 1

c) Educação pela pesquisa: desafio para o Ensino de Biblioteconomia na UFSC

$>$ A palestra como um todo $\quad 27$

$>$ Enfatizou a necessidade de desmistificar o ato de pesquisar $\quad 19$

$>$ Enfatizou a importância da pesquisa no ensino 11

$>$ Mostrou a influência da pesquisa sobre as pessoas $\quad 10$

$>$ Quando fez um desafio ao Curso de Biblioteconomia ao perguntar qual

o diferencial deste curso em relação aos demais em biblioteconomia 2

$>$ Enfatizou a falta de pesquisadores e escritores 2

$>$ Chamar a atenção para o uso da informação 1

Questão 3 - Para você, quais foram os pontos fracos no conteúdo e na apresentação dos seguintes temas:

a) Marcos do Ensino de Biblioteconomia na UFSC

$>$ Apresentação apática / muitos números / leitura de transparências 25

$>$ A apresentação como um todo

$>$ Faltou entrosamento dos apresentadores

$>$ Foi pouco tempo para apresentação 2

$>\mathrm{O}$ curso ainda é muito acadêmico 2

$>$ As mudanças na primeira revisão do Curso 1

$>$ Faltou participação 1

b) Educação sem informação, informação sem educação

$>$ A pouca participação, inclusive dos professores 5

$>$ Faltou apontar soluções $\quad 4$

$>$ A possibilidade de extinção do curso

$>$ A palestra como um todo $\quad 3$

$>$ Pouco tempo para palestra 3

$>$ Repetição do XXI ENEBD 3

$>$ O sistema atual não induz a pensar, apenas informa 2

$>$ A falta de dados no Brasil 1

$>$ Palestrante enfatizou demais a sua opinião pessoal 1

$>$ Desmotivou os profissionais de bibliotecas especializadas $\quad 1$

$\begin{array}{ll}>\text { Traz muita teoria que não se usa na prática } & 1 \\ >\text { Obscuro } & 1\end{array}$

$>$ Enfatiza razões para a falta de bibliotecários em bibliotecas públicas 1

c) Educação pela pesquisa: desafio para o Ensino de Biblioteconomia na UFSC

$>$ Palestrante não prende o espectador / repetitivo / cansativo 18

$>$ A palestra como um todo $\quad 13$

$>$ Pouco tempo para o debate 4

$>$ A falta de pesquisa na graduação $\quad 2$

$>$ A linguagem foi muito técnica $\quad 2$

$>$ Faltou enfocar os pontos construtivos $\quad 2$

$>$ Faltou trazer alguns professores que fizeram pesquisas $\quad 1$

$\begin{array}{ll}>\text { Faltou mais profundidade } & 1\end{array}$ 
$>$ Linguagem pouco objetiva

$>$ Não foi dito como se aprende a pesquisar no curso de biblioteconomia 1

Questão 4 - A "Exposição eletrônica: 25 anos de Biblioteconomia em Santa Catarina" lhe despertou:

a) Muito interesse ( ) - Por que?

> Dá visão geral da evolução do Curso de Biblioteconomia 28

$>$ Mostra a biblioteconomia ganhando espaço no meio tecnológico 20

> Dá melhor visualização da biblioteconomia 19

$>$ Despertou mais interesse pela discussão 5

$>$ Incentiva a navegar $\quad 3$

$>$ Agrega qualidade e rapidez $\quad 3$

$>$ Facilita a assimilação de assuntos $\quad 3$

$>$ Mostra a teoria transformando-se em prática 3

$>$ Pela forma de organização e exposição 2

b) Razoável interesse ( ) - Por que?

$>$ Talvez por estar na primeira fase 2

$>$ Por saber que o CED já está na Internet 2

$>$ Mesmo organizada, tirou a atenção do público 1

$>$ Por que diariamente tenho contato com a Internet 1

$>$ Trouxe tema de nosso interesse 1

$>$ Foi muito formal 1

$>$ Está ligado ao curso de biblioteconomia

$>$ A história das escolas de biblioteconomia é quase a mesma 1

$>$ Já tinha visto em sala de aula 1

$>$ Deveria ser mais real $\quad 1$

$>$ Devido as falhas

c) Pouco interesse ( ) - Por que? SEM RESPOSTAS

d) Nenhum interesse ( ) - Por que? SEM RESPOSTAS

\section{CONSIDERAÇÕES FINAIS}

O Encontro OS 25 ANOS DE EDUCAÇÃO EM BIBLIOTECONOMIA NA UFSC torna imprescindível por em perspectiva o seguinte:

a) Expôs de forma positiva o Curso de Biblioteconomia e o Departamento de Biblioteconomia e

Documentação, na medida em que levou a uma outra maneira, mais dinâmica, de sistematizar algumas etapas do processo de formação de bibliotecários na UFSC;

b) Induziu uma dinâmica de trabalho em equipe, fortalecendo a interação no Departamento de

Biblioteconomia e Documentação;

c) Cobrou a reflexão dos alunos do Curso ao aplicar um instrumento de avaliação sobre conteúdo e forma dos temas apresentados;

d) Sugeriu que a educação bibliotecária necessita promover mais freqüentemente eventos desta natureza e se beneficiar das opiniões dadas nas avaliações feitas pelos participantes.

A avaliação, conforme os dados já expostos, nos diz e nos interroga sobre o seguinte:

a) o estudante de biblioteconomia da UFSC está aberto a conhecer melhor o Curso e a área de Biblioteconomia.

Como podemos corresponder bem a isso?

b) Palestras mais contundentes, que analisam a realidade da sociedade presente, estimulam um maior interesse dos alunos.

Como podemos corresponder a isso e resgatar tal discussão no dia-a-dia do Curso?

c) A pesquisa precisa ser desmistificada sempre, e mais.

Como o Curso de Biblioteconomia da UFSC quer fazer isso?

Enc. Bibli: R. Eletr. Bibliotecon. Ci. Inf., ISSN 1518-2924, Florianópolis, Brasil. 
d) As apresentações feitas por professores da UFSC tiveram uma dinâmica, até certo ponto, desmobilizadora. Por quais motivos isso acontece?

Estas questões requerem a reflexão dos Professores do Curso de Biblioteconomia, em especial, dos que compõem o Departamento de Biblioteconomia e Documentação.

Disponibilizado na WWW em 26/04/1999. 